\title{
Research on the Application of Situational Interactive Teaching Method to the Financial Management Course
}

\author{
Na Wang \\ Harbin Finance University \\ Harbin, China
}

\begin{abstract}
The situational interaction has subverted the traditional teaching method. Professor Zhu Qiang of Nanjing Normal University puts forward that the better teaching should be a kind of teaching with a sense of involvement during the training to the teachers in colleges and universities. Based on the specific content of Situational Interactive Teaching, this paper studies the application of this teaching method in the classroom teaching of the main courses of financial management major in applied undergraduate colleges and universities.
\end{abstract}

Keywords-situational interactive teaching method; financial management; research on application

\section{INTRODUCTION}

Not all the knowledge points in all the courses can make the students cheer up. Facing the college students born after 2,000 , who are the indigenous people of the internet, the traditional teaching mode of "taking teacher as center, relying on chalk, mouth and PPT" can no longer meet the needs of the new era. If I show you, you may remember; if I do it together with you, you will never forget. The method of letting the students participate in teaching, which is called as "bring in", and now known as "involving in", is to make the participators think and discuss in their own room to simulate their inner feelings. The way of discussing problems and the answers you get via this method will be unforgettable for life. This is the "Situational Interactive Teaching Method" will be discussed in this paper.

\section{The ORIGin OF Situational InTERActive Teaching}

Situational Interactive Teaching originated from the theory of Situated Cognition, which was developed in the West in the 1980s. Its early research came from Dewey, Wigowski, Leon Geoff and other scholars, that is, "knowledge is not regarded as the internal representation of psychology, but as the attribute and interactive product between individual and social or physical situation. Therefore, participation in the general cultural practice based on social situation is the source of the formation of individual knowledge structure. The learning of a single individual is flawed, because people are social, just as the cognition and behavior studied by the theory of Situated Cognition are interactive, knowledge should be presented in the real situation, and the cognitive process should be constructed, guided and supported by the situation.

\section{The SPeCific CONTENT OF Situational Interactive TEACHING}

\section{A. Situational Interactive Teaching}

Situational Interactive Teaching Method refers to a teaching method in which teachers purposefully introduce or create vivid scenes with certain emotional color and vivid image to attract students' certain attitude experience, guide them to participate, practice and share, so as to help students understand the teaching content and promote them to improve in "knowledge - skills - psychology" aspects.

Using situational interactive teaching can deepen students memory, make students understand knowledge more deeply, and achieve the effect of teaching and learning.

\section{B. The Design Principle of Situational Interactive Teaching}

Firstly, it is participation. The same people come up each time when different roles are played and discussed in groups, what should we do? Distribution, distribute the job to everyone to avoid the decentralization of responsibility, the role should be set rather than simply say "let's discuss it", For example: role one, moderator, each discussion with a different moderator; role two, timekeeper; role three, recorder; role four, future speaker. The roles should be changed in the next round.

Secondly, it is learning acquisition. The process of discussion is the process of learning acquisition. The content of situated interactive should cover learning circle.

Thirdly, it is the field control. Teachers should have a certain ability to control the field.

Finally, it is fun. The game designed should be full of fun.

\section{Three-step Strategy in the Process of Situational Interactive Teaching}

For the 1st step, it includes background explanation, course related introduction, theme explanation and content introduction. 
For the 2nd step, it includes situation analysis, role allocation and interactive sharing.

For the 3rd step, it includes sharing views and summarizing contents.

\section{Skills of Situational Interactive Teaching}

Teachers should have empathy, identify with students' differences, and respect students' learning styles.

FBA rule: FBA corresponds to three English words: Feature, Advantage and Benefit, that is, the rule of property, function and benefit. The introduction in this order is the structure of persuasive speech, and its effect is to let customers believe that you are the best. In the Situational Interactive Teaching, teachers should constantly summarize and attribute at different stages to achieve the desired teaching effect.

Process control should be humorous-joyful-interesting, interactive-participatory-shared, simulated-unbiased-multi presupposed.

\section{CASES OF Situational InTERACTIVE TEACHING METHOD TO THE FinANCIAL MANAGEMENT COURSE}

Financial Management, Enterprise Financial Analysis, Cost Accounting and Management is the three core courses of financial management major in application-oriented undergraduate colleges, we choose three different knowledge points from three core courses to study the application of Situational Interactive Teaching Method.

\section{A. Situational Interactive Teaching Design of Financial Management}

Teaching content: Mastering the objectives of financial management.

In the nineties of the last century, Beida Qingniao became a shareholder in Beijing Tianqiao shopping mall, which entered the IT industry. In the process of industrial transformation, the problem of employee placement conflicts with the financial management goal of the enterprise. In speaking of the teaching procedure, firstly, learn the knowledge points, then introduce the background of the case and the situated interactive rules to the students. In the situational interaction class, students discuss solutions in groups and roles. There is a moderator, a chairman, a secretary of the board of directors, a manager of human resources department, a representative of laid-off employees, and a recorder in the group. In the first round of discussions, we all adhered to our own views and tried to seek more benefits for ourselves. Few agreed measures were put forward after each expressed his own views. When the host announced the role exchange by redrawing lots and entered a new round of discussion, some students were able to think about rational negotiation solutions, and gradually everyone began to accept the plan to minimize the loss of the other party, and finally reached an agreement. Each group will discuss the solution with the teacher in class. When discussing the advantages and disadvantages of each method with the students, the teacher constantly summarized and attributed, reminded the students of the relevant content of the goal theory of financial management, and finally determined the optimal solution that everyone agreed.

\section{B. Situational Interactive Teaching Design of Enterprise Financial Analysis}

Teaching content: Cultivating the decision-making ability of students

There is a part is strategic analysis in the course of Enterprise Financial Analysis, when the content of strategic analysis is near the end, the case of Pirates Divide Gold Coins in economics is introduced for situational interaction. Case content: Five pirates got 100 gold coins. They divided them on a ship. How to divide them? Each person puts forward an allocation scheme, and the order of proposal shall be determined by the form of drawing lots. The person who draws No.1 shall put forward the scheme first. If more than half of the scheme's people agree, the scheme shall be approved, and the allocation shall be made according to this. Otherwise, No. 1 will be thrown into the sea to feed the fish, and then No. 2 will put forward the distribution plan. Assuming that every pirate is extremely intelligent and rational, and knows what other people think, the question is: what kind of distribution scheme is proposed by No. 1 to save his life?

First of all, divide the students into several groups. If it is a small class, five students in a group, draw lots to determine the corresponding pirate number. Each student simulates the pirate and publishes his own plan in order. If it is a large class, 6-7 people in a group, draw lots to decide the three roles of pirate, host and recorder. The teacher is the timekeeper of the whole audience. At the appointed time, each group handed in the distribution plan, which was published in a kind of mobile app teaching software called "rain class" developed by Tsinghua University in China, and everyone could see it. According to the teaching experience, there will be four situations. The first situation is that no scheme has been selected. The second situation is that there are different opinions in the group, and some people have been thrown into the sea. The third situation is that the scheme proposed by No. 1 barely passed, but deviated from the answer. The fourth situation is that the answer proposed by one of the students in the group is close to the correct answer, but not good enough, and other students have different opinions. At this time, in the process of stage summary and comparative analysis of each group's answers, teachers guide students' thinking direction with theory to improve their analysis and decision-making ability. After summary, they draw lots for the second round of discussion, and the results of discussion will be more and more close to the correct answers. In the interaction process, everyone has been thoughtful and gained.

\section{Situational Interactive Teaching Design of Cost Accounting and Management}

Teaching content: Learning four ways to allocate production costs between products being processed and finished products.

The difference between the situated interactive design of this part and (i) (ii) is that this interaction is an exam, and the exam results are retained as mid-term scores. First of all, the 
whole class was randomly divided into groups through the "rain class" teaching tool. After the groups were divided, the students checked their group numbers through mobile phones and found their seats within one minute according to the teacher's prompts. The teacher distributed materials to each group. There are four manufacturing enterprises with different industry backgrounds in the materials. The team leader will distribute the materials of four enterprises to different members. Each student will introduce the characteristics of various indicators of the company in the group after receiving the materials. You need to discuss which method the enterprise chooses to realize the distribution of production cost between the products being processed and finished products. The team leader is responsible for communicating the theoretical knowledge and assisting the team members to complete the task. After the task is completed, the team leader is responsible for organizing the team members to randomly select task not being completed by themselves and to list and sign the name and student number. Finally, the teacher will give the comprehensive scores in groups.

It should be noted that the cost accounting and management is the examination class, and the class hours are 30. Students often do not pay attention to the study of the examination class, and often do not concentrate enough in the class. Through this form of Situational Interactive Teaching, students can avoid the phenomenon of classroom gap, and achieve the purpose of learning to use, and enhance the ability of team cooperation.

\section{CONCLUSION}

The Situational Interactive Teaching Method, with students as the main body and teachers as the guidance, has better cultivated students' thinking ability and the ability to solve problems by themselves. However, attention should also be paid to the internal differences of different knowledge points of the course. When adopting the Situational Interactive Teaching Method, we should fully study the characteristics of the course content itself, design appropriate scenes for the content, and draw inferences from one instance. We can't simply apply the teaching design principles and three-step strategies of Situational Interactive Teaching Method.

\section{REFERENCES}

[1] Xiong Hanfu. Application Value and Method of Situated Simulation Teaching in HRM Teaching [J]. Human Resource Management 2010. (12) (in Chinese)

[2] Lu Hongyan. Application and Exploration of Situated Simulation Teaching Method in the Course of Financial Analysis [J]. Business Accounting 2014. (17) (in Chinese)

[3] Zhao Jinjin. Discussion on the application of Situation Simulation in Training [J]. Journal of Higher Education 2016. (14) (in Chinese)

[4] Wang, N (Wang, Na), Research on Practical Teaching Reform of Undergraduate Talents Training in Application-oriented Financial Management Major Advances in Social Science Education and Humanities Research Volume: 205 Page: 184-187 Publication Year: 2018. (in Chinese)

[5] Harbin Finance University. Learning Experience of Training Class for Improving Professional Ability of Key Teachers of Harbin Finance University [G]. Academic Affairs Office of Harbin Finance University, 2019. (9) (in Chinese) 